\title{
LEXICAL DENSITY AND GRAMMATICAL INTRICACY IN DEBATERS' SPEECHES
}

\author{
Putry Amelia, Tengku Silvana Sinar, Tengku Thyrhaya Zein \\ Universitas Sumatera Utara (USU), Medan, Indonesia \\ E-mail: putrystr2710@gmail.com
}

Received: 13 May 2020

Accepted: 08 June 2020

\begin{abstract}
This paper entitled "Lexical Density and Grammatical Intricacy in Debaters' speeches (Case Study of National University Debating Championship 2018)" discusses the lexical density and grammatical intricacy to identify the level of lexical density and grammatical intricacy in debaters' speeches conducted by means of descriptive qualitative method. The theories supporting this thesis are the ones proposed by Ure, Halliday, and Simon Quinn. The data source in this thesis were debate speech from Main Grand Final round of NUDC 2018 which are Opening Government team (Prime Minfister and Deputy Prime Minister) and Opening Opposition team (Leader of the Opposition and Deputy Leader of the Opposition) taken from youtube video of NUDC 2018, Malang. The data in this study were lexical items for lexical density and clauses for grammatical intricacy. The step passed in this analysis are collecting the data by transcribing the debate speech into text, identifying the lexical items and clauses, and concluding the analysis. The result of this thesis shows that lexical density and grammatical intricacy of Prime Minister $=40.95 \%$ and 3.43, Deputy Prime Minister $=42.44 \%$ and 2.72 , Leader of the Opposition $=46.14 \%$ and 2.91 , and Deputy Leader of the Opposition $=47.90 \%$ and 3 . Thus, both the level of lexical density and grammatical intricacy in debaters' speeches account for higher density and intricacy, so debaters' speeches represent much information due to many lexical items as the proportion of running words and indicate that clause complex is more dominant than simple sentence.
\end{abstract}

Keywords: lexical density, grammatical intricacy, debate, lexical items, clause

\section{Introduction}

Debate has been a popular platform in 21st century in the terms of conveying ideas, knowledge and thoughts. Shan (2005:21) states that debate is defined as two groups of people on opposite sides of the issue discussing an agreed topic upon rules, and the judges listen to both different sides of the argument, choosing the winning team based on the reasoning and evidence provided. In Indonesian context, debate is considered as a means for students to exercise public speaking ability which is manifested through the existence of a lot of competitions. In Indonesia, debate competitions either local, regional, or national scale have been numerously conducted. For instance, in varsity level, National University Debating Championship (NUDC) is one of the annual debate competitions. The competition consists of two categories which are Main and Novice categories. The competition is 
compulsory and important to be followed by the varsity students since the Ministry of Education has provided particular funds to encourage each individual to exercise their public speaking ability through debate. NUDC adopts the British Parliamentary debate format which is also applied in the World University Debating Championship (WUDC).

Debate does not only trigger every individual to win, but also one of the spoken languages that aims to exercise speaking ability and fluency. Byrne (1993) states that debate helps debaters to explore and develop their speaking skills effectively. Thus, debaters need not only speak in front of different audiences and judges, but they also need to be able to construct their argument in applying the best principles of public speaking to select, arrange, and present their materials. In applying the principles, it takes forms on how the debaters construct each sentence and choose appropriate words related to the debate topics. Either beginners or professional debaters, they use various complexity of language. As a result, the complexity of language of the speakers is challenged when they deliver their speech. Complexity of language in debaters' speeches can be seen through selected lexical items and types of clauses used by the debaters.

The complexity of language is proposed by Halliday (1985a) in a theory of Systemic Functional Linguistics (SFL). Based on the theory, complexity of language typically deals with grammatical intricacy, lexical density, nominalization, grammatical metaphor and thematic structure. Johansson (2008:61) states that Lexical Density (LD) deals with the total number of lexical items or content words (i.e. nouns, verbs, adjectives and some adverbs) in the text. Halliday (2008) also states that the lexical density refers to the complexity of language that results from the development of words. On the other hand, Grammatical Intricacy (GI) is an important concept in characterizing complexity of language. It refers to how often a clause complex appears in a text in comparison with simple clauses.

The example of LD and GI representation in debaters' speeches:

Lexical Density (LD) representation

Eg: Opening government believes in the idea that it will discriminate the minority that they really need to be protected by law by the government.

Grammatical Intricacy (GI) representation

Eg: This method is not according to what society wants, because it contains unacceptable and amateurish acts to promote their own interest. Not only that society will perceive this as a selfish act, but also cruel and inhumane. Like the case of women march, we can see many societies condemn this march because it was not emphasizing on the positive values of women such as independency and strong will. But it focused more on attacking the men by creating horrific graphics that was disgusting and unacceptable.

Based on the data taken from World University Debating Championship (WUDC), the LD representation above represents that there are five nouns (government, idea, minority, law, government), one adjective (opening), four verbs (believes, discriminate, need, protected), and one adverb (really). It means that there are eleven lexical items and thirteen grammatical items in this sentence, giving a proportion of eleven lexical items out of twentyfour items in total, and using Ure's (1971) original method, the lexical density would be forty-five per cent or 0.45 .

From the $\mathrm{Gl}$ representation above, there are 6 ranking clauses and 3 clause complexes, giving the grammatical intricacy index of 2 for this extract. Daller, Van Hout \& Treffers-Dalle (2003) defines that lexical density is the term which refers to measurement 
that quantifies the lexical richness of texts. It shows for how many different words are used in a text. In addition to that, Halliday (1985) explaines that texts with a lower density are more easily understood and spoken texts have lower lexical density levels than written texts. It is because lexical density shows the complexity of words within text.

As pointed out by Ure (1971:445), a large majority of the spoken texts have a lexical density of under $40 \%$, while a large majority of the written texts have a lexical density of $40 \%$ or higher. It means that lexical density is the representation of content words in a text/sentence and high portion of LD characterizing a text to be in a written mode. Lexical density can be observed by using Ure's and Halliday's method. In this study, Ure's method is applied.

On the other hand, grammatical Intricacy relates to the number of sentences in the text. The high ratio or index of $\mathrm{Gl}$ is the indicator of a text to be categorized as a spoken language. It means that high index of $\mathrm{Gl}$ can be used to characterize a text to be in spoken mode. This is all related to how much information is introduced in a clause complex which can contain more than one simple clause. Classification of clauses (sentences) is applicable to the determination of grammatical intricacy (complexity) of a text. If in a text there are more clause complexes than simple clauses, it can be said that the text is more complex in the sense that it presents more information. Grammatical intricacy is measured as the number of ranking clauses in the clause complex (Halliday, 2008). In this study, Halliday's (2008) method is applied.

Based on the explanation above, it can be said that lexical density and grammatical intricacy are important to be analyzed as they both represent the amount of information that is needed in constructing an argument in debate speech. Thus, the study focuses only on analyzing the lexical density and grammatical intricacy in debaters' speeches. The study analyzes the lexical density and grammatical intricacy in debaters' speeches in Main Category of NUDC 2018 and debaters have already got basic understanding of the debate. The study decided to choose NUDC 2018 because the YouTube video of NUDC 2019 is not complete due to the reasons that some of the debaters are not consented to be recorded. This study also attempts to investigate the characteristics of debaters' speeches in terms of lexical density and grammatical intricacy and to characterize if those debaters' speeches can be categorized into written or spoken mode.

\section{Literature Review}

Recently, the SFL approach is used world-wide, especially in language education, and for a number of purposes like discourse analysis. As Halliday and Matthiessen (2004) state, SFL is a linguistic theory that considers language as a part of social system and a meaningmaking resource. This statement explains that language perceives how people use language to establish and produce meaning to fulfill their communicative purpose in social contexts.

Moreover, SFL, with regards to data, does not deal with the manner of the language representation or process in the human brain, but would rather try to view discourses produced in the form of written or oral language and what is contained is the texts that are produced. Since the use of language becomes the concern of SFL, great importance is placed in the function of language, such as what language is used for rather than what language structure is all about and the manner by which it is composed (Matthiessen \& Halliday, 2004). Thus, SFL examines the text in four ways which are Context, Semantics, Lexicogrammar, and Phonology. The channel of communication either spoken or written language is being used as a mode of action or reflection. Eggins (2004: 93) summarizes the linguistic 
difference that corresponds to our two polar extremes of a spoken and a written language situation.

However, Eggins (2004: 94) argues that there are two main linguistics features that are highly sensitive to mode variation, the degree of grammatical intricacy and the lexical density of the language chosen. These features are responsible for perhaps the most striking differences between spoken and written language. Halliday in his book Spoken and Written Language (1985:62) also explains the significant distinction between written and spoken language. The first one is Density, the density with which the information is presented. Relative to each other, spoken language is sparse, and written language is dense. The second is Intricacy, the intricacy with which the information is organized. Spoken language is more intricate than written language. In addition to that, Halliday and Matthiessen (2004) affirm that written language is normally complex when it has high lexical density. It stores a large number of lexical items into each clause. On the other hand, spoken language becomes complex by being grammatically intricate.

Lexical density is the term most often used for describing the proportion of content words (nouns, verbs, adjectives, and often also adverbs) to the total number of words. The concept of density refers to a kind of complexity that results from the development of words. Halliday (1985) says that lexical density relates to the notion of the lexico-grammar in terms of the level of wording in language. It is a measure of the density of information in any passage of a text, according to how tightly the lexical items (content words) have been packed into the grammatical structure (Halliday, 2005:83). He defines lexical density as the number of lexical items, as the proportion of the number of running words. Lexical density can be measured by distinguishing the grammatical items from lexical items. Halliday (1985b) says that grammatical items or function words come in a closed system compromising of determiners such as articles, pronouns, most prepositions, conjunctions, some classes of adverbs and finite verbs. On the other hand, lexical items or content words are named lexical as they function in lexical sets which show that that they are part of an open system rather than closed sets (Halliday, 1985).

Grammatical intricacy relates to the number of clauses in a text as a proportion of the number of sentences in the text. It refers to how simple clauses in a clause complex are connected by means of logico-semantic types at the clausal level. As such, grammatical intricacy helps construe the logical meta function of language (Halliday, 2008). GI also refers to how often a clause complex appears in the text in comparison with simple clauses. It is accepted that any text has a different level of intricacy (complexity). This is all related to how much information is introduced in a clause complex which can contain more than one simple clause. Although grammatical intricacy tends to be used for the analysis of complexity of spoken language as argued by Halliday, it is worth including in the measurement of written text complexity since it can show the complexity not only at the level of words but also at the level of clauses. Grammatical intricacy is important to be uncovered because a text is said to be difficult because of the intricacy of information. A simple clause is easier to understand in the sense that the amount of information presented is less than that of clause complex. In other words, a clause complex as indicated in functional grammar contains more information than a simple clause. The measurement of grammatical intricacy can be done by the proportion of ranking clauses per total number of clause complexes (Halliday, 2008). In this case, the level of Grammatical Intricacy is counted by analyzing high and low level of grammatical intricacy (complexity) of a text. If the number of clause complex is more dominant than simple sentence in a text, it means that the text has high 
level of $\mathrm{Gl}$, and on the contrary if the number of clause complex is lower than simple sentence, this means that the text has low GI.

The level of intricacy can be found by finding the ratio between the simple clauses and clause complexes in the real analysis, and a simple clause may be regarded as consisting subject and predicate. Every type of clauses has a different level of difficulty. Various studies show that clause complexes are more difficult to process than simple clauses, reflecting their relatively greater intricacy. By then, Halliday (2005) argues that the feature of grammatical simplicity shows that written language tends to use few clauses per sentence.

Concerning debate, Freeley and Steinberg (2009: 6) argues that debate is the process of advocacy, away of delivering judgement in order to achieve a decision in their own minds. Debate is a particular form of argument. It is not a way of reconciling difference- that is a misconception. The purpose of a debate is not for two disputing parties to leave the room in agreement. Instead, through the debate between them, others will form a judgment about which of the two to support (Smith, 2011: 1). Thus, debaters need to decide what the words of the topic mean for the purposes of this debate. This is known as 'definition'. They need to think of some reasons why your side of the topic is true. These reasons are known as 'arguments' that speakers try to join the arguments together into a single 'case approach'. Speakers also need 'split' which divides the arguments between what speaker knows what he or she has to present. They are needed in formal debate to make audience understand. Debate needs debaters, adjudicators, chairperson, time keeper and audiences. The debaters become the main players here; they should deliver the contradictory arguments of the motion with their opponent. When having the speech, they should consider the manner, matter and method.

\section{Research Method}

This study is a descriptive qualitative research. Patton and Cochran (2002) state that qualitative research is characterized by its aims and its methods which generate words, rather than numbers, as data for analysis. It means that the data of the study are analyzed by describing, identifying and analyzing the texts. Descriptive research means that the data of this study are described or explained. This kind of research describes and explains a phenomenon as it is. To do the research, a document or content analysis is applied.

The data of this study are lexical items (content words) and clauses in debaters' speeches. Lexical items are used for the analysis of lexical density and clauses are used for the analysis of grammatical intricacy. The source of data was debaters' speeches from the two teams in main grand final round in National University Debating Championship (NUDC) in 2018 taken from https://www.youtube.com/watch?v=4XfX02rlO0g\&t=670s. The NUDC 2018 was held in University of Negeri Malang on August 19th 2018. The teams are Opening Government (University of Sriwijaya) and Opening Opposition (Institute Technology of Bandung). The opening government consists of two debaters which are Prime Minister and Deputy Prime Minister. On the other hand, opening opposition consists of Leader of the Opposition and Deputy Leader of the Opposition.

These data collection activities typically are carried out in close proximity to a local setting for a sustained period of time. Such data are not usually immediately accessible for analysis but require some type of processing: Raw field notes need to be expanded and typed up; audio recordings need to be transcribed and corrected, and photographs need to be documented and analyzed". In this research, the technique of collecting data that the writer uses is Document Study. Document Study is the process of learning from what is 
written and seen from the document. The document in this research is spoken texts which are the debaters' speeches from https://www.youtube.com/watch?v=4XfX02rlO0g\&t=670s.

In the procedures of data collection, the researcher provides several steps of collecting the data.

1. Searching youtube video on https://www.youtube.com/watch?v=4XfX02rlO0g\&t=670s.

2. Downloading youtube video of all debaters' speeches in main category. In Main Category, the debaters' speeches consists of eight debaters.

3. Watching youtube video of eight debaters in Main Category

4. Selecting the four debaters' speeches based on Opening Benches

5. Transcribing the audio into a text

6. Reading the text speeches of four debaters

7. Identifying the lexical items based on LD

8. Identifying the clauses based on GI

9. Collecting the lexical items and clauses of text speeches

10. Puting the data into the table

In this research, the data condensation is divided into Selecting the lexical items and clauses, Focusing on the number of lexical items and clauses, Simplifying the data, classified into nouns, adjectives, verbs and adverbs and clauses are classified into independent and dependent clause and Transforming the data by putting the data into the table. For the analysis of LD, the study employs the methods proposed by Ure (1971) which is discussed above as central measurements to lexical density exploration in texts.

\section{(Ure's method):}

Table 3.2. Ure (1971), LD measurement.

\begin{tabular}{|c|c|}
\hline \multirow{2}{*}{ Lexical Density } & Number of Lexical Items $\times 100$ \\
\cline { 2 - 2 } & Total number of words \\
\hline
\end{tabular}

Regarding the measurement, if the number surpasses forty percent, it accounts for higher lexical density.

Grammatical intricacy $(G I)$ is calculated using the formula proposed by Halliday (2008).

Table 3.3. Halliday (2008), GI measurement.

\begin{tabular}{|l|l|}
\hline \multirow{2}{*}{ GI } & Total Number of ranking clauses \\
\cline { 2 - 2 } & Total number of clause complex \\
\hline
\end{tabular}

The intricacy of grammar is captured in terms of how many clauses are joined together to form a clause complex, and the higher the index is, the more intricate the text is (Castello 2008:97).

After the verification of the data is done, the data for lexical density and grammatical Intricacy are concluded into the following tables.

Table 3.4 Lexical Density and Grammatical Intricacy of 4 debaters' speeches. 


\section{Results and Discussion}

The term lexical density refers to proportion of lexical items (verb, noun, adjective, and adverb) to the total amount of running words in a text. On the other hand, grammatical intricacy deals with the total amount of ranking clause in clause complex. Based on the analysis of data, it is found that Prime Minister (PM) speech has 584 lexical items among 1426 words and has 37 clause complexes that consist of 127 ranking clauses, Deputy Prime Minister (DPM) speech has 674 lexical items among 1588 words and has 59 clause complexes that consist of 161 ranking clauses, Leader of the Opposition (LO) speech has 712 lexical items among 1543 words and has 57 clause complexes that consist of 166 ranking clauses, Deputy Leader of the Opposition (DLO) speech has 709 lexical items among 1480 words and has 48 clause complexes that consist of 144 ranking clauses.

\begin{tabular}{|c|c|c|c|}
\hline No. & Debaters' speeches & $\begin{array}{c}\text { Lexical } \\
\text { Density } \\
\text { (\%) }\end{array}$ & $\begin{array}{c}\text { Grammatical } \\
\text { Intricacy }\end{array}$ \\
\hline 1. & Prime Minister (PM) & 40.95 & 3.43 \\
\hline 2. & Deputy Prime Minister (DPM) & 42.44 & 2.72 \\
\hline 3. & Leader of the Opposition (LO) & 46.14 & 2.91 \\
\hline 4. & Deputy Leader of the Opposition (DLO) & 47.90 & 3 \\
\hline & Average Score & $44.35 \%$ & 3 \\
\hline
\end{tabular}

\section{Conclusion}

After analyzing the lexical density and grammatical intricacy in debaters' speeches from the opening government and opening opposition team in NUDC 2018, the researcher concludes that Lexical density in four debaters' speeches surpasses $40 \%$ with the average score $44.35 \%$. It indicates that the four debaters' speeches account for higher lexical density. The highest lexical density among the four debaters' speeches is found in Deputy Leader of the Opposition (DLO) speech (47.90\%), while the lowest lexical density is found in Prime Minister (PM) speech (40.95\%). It also demonstrates that the winning team (Opposition team) consists of LO (46.14\%) and DLO (47.90\%) accounts for higher lexical density compared to the losing team consisted of PM (40.95\%) and DPM (42.44\%). This means that the lexical density determines the team to be the winning or losing team since lexical density itself represents the amount of information presented in debater speech. On the other hand, the four debaters' speeches show the high level of GI, proven on how clause complex is more dominant than simple sentence in debaters' speeches. It indicates that debater speech is said to be difficult because of the intricacy of information. It is because clause complexes are more difficult to process than simple clauses, reflecting their relatively greater intricacy. Thus, the researcher concludes that debaters' speech accounts for higher lexical density and high level of grammatical intricacy. By this, in terms of lexical density, debaters' speech can be categorized as written language for having lexical density above 40 $\%$. On the other hand, in terms of the level of GI, debaters' speech can be categorized as spoken language for having high grammatical intricacy.

\section{References}

Byrne, D. (1991). Techniques for Classroom Interaction. Cambridge: Cambridge University Press. 
Castello, E. (2008). Text complexity and reading comprehension tests. Bern: International Academic Publishers.

Daller, H., van Hout, R., \& Troffers-Daller, J. (2003). Lexical richness in the spontaneous speech of bilinguals. Applied Linguistics, 24/2, 197- 222.

Eggins, S. (2004). An introduction to systemic functional linguistics (2nd Ed.). New York: Continuum.

Freeley J, Austin and David L. Steinberg. (2009). Argumentation and Debate: Critical Thinking for Reasoned Decision Making. Boston: Wadsworth Cengage Learning. Halliday, M. A. K. (1985a). An introduction to functional grammar. London: Arnold.

Halliday, M. A. K. (1985). Spoken and Written Language. Hong Kong: Oxford University Press. Halliday, M. A. K. (1985). Spoken and Written Language. Victoria: Deakin University

Halliday, M. A. K and Matthiessen. (2004). An introduction to functional grammar. London: Hodder Headline Group.

Halliday, M. A. K. (2008). Complementarities in language. Beijing: The Commercial Press.

Johansson, Victoria. (2008). Lexical diversity and lexical density in speech and writing. Lund University: Lund University Press.

Patton, M. and Cocharn, M. (2002) A Guide to Using Qualitative Research Methodology. Médecins Sans Frontières, Paris.

Shan, L. (2005). The Effect of Debate on Oral Communication Skills among University

Students in Taiwan: A case study. National Tsing Hue University, Taiwan.

Smith-Harvey, Neill. (2011). The Practical Guide to Debating Worlds Style. New York, London: International Debate Education Association.

Ure, J. (1971). Lexical density and register differentiation. In G. E. Perret \& J. L.M. Trim (Eds.). Applications of linguistics: Selected Papers of the Second International Congress of Applied Linguistics (pp. 443-452). Cambridge: Cambridge University Press.

\section{APPENDIX}

\section{Prime Minister}

The old method of Indonesian liberals is they said that whatever even if when the political candidate is very bad you still have to have the choice because it is democracy to begin with. You have to participate because it is your obligation to begin with. Right now, under OG we want to change the method of our campaign to begin with. We are going to stop all the campaigning that says that you have to acknowledge your voice in the form of choosing any candidate even when the moment you hate both of the candidate to begin with. What is the method of campaign of Indonesian liberals under OG going to be look like? Number one, we say that we are still going to do the political education to begin with. We are still going to give the information of the candidates for example and ensuring the people knows the candidate to begin with. We will not stop playing on the rhetoric that voting is your obligation to begin with even we are going to support the abstention because we are going to say that it is a legitimate choice for you to abstain in the democracy to begin with. There are four thing I'm going to argue in my speech. On the principle, why in the democracy abstain is a legitimate choice and second how it fits the Indonesian liberal interest and last the third why it is important and lastly why it is going to be beneficial.

Going to the first, on the principle why in democracy abstention is a legitimate choice and it is also a part of participation of democracy. What you need to understand is that the 
principle of democracy is the process of acknowledging people choice and people voice regardless of what is their choice to begin with right. Therefore, we cannot force people in the democracy. Therefore, in the term of voting, we're always having the fair campaign to begin with and we should not force people to begin with. We say that the moment when we are people abstain is that that they are not irrational or they are ignorant to begin with. But we say that part of the reason when people abstain is first because they believe that there is no any policy coming from the candidate cannot benefit themselves.

On second, they believe that the political candidate at the end of the day unable to bring the voice inside of parliament and manifest it into a policy that is going to benefit them to begin with. Therefore, we characterize to you that abstention is not an irrational choice but it is a rational choice coming from your needs to begin with that we have to support it right. Why is this harmful at the end of the day the moment when we are still forcing people to vote inside of democracy to begin with. We say this is exactly going to be bad because at the end of the day the society is going to be randomly choose because they are trapped under that voting is the obligation to begin with. We say this is something that is bad to begin with right. Because at the end of the day the leader that is going to be chosen is also not going to be favorable under opposition of the house right.

The comparative is this, at least under our side of the house the moment when we are abstain and the candidate and the political candidate leader that is winning is also not within your favor. We say that first, morally you are not going to have a burden to begin with because you are not complicit in making this particular candidate winning to begin with. But second, we are going to have a legitimate reason for you to criticize the government to begin with. Look, currently we have a raising people like Panji Pragiwaksono, such or example the Indonesian liberal figures he is also trying to ciritize the government but their voice seems to be blunder and irrational because they are seen as someone that is changing the stance to begin with right, on how such for example in the past such for example Panji trying to support ANIS but at the end of the day they are going to also advocate to free speech in the case of ahok to begin with. Therefore, people will less likely to hear the voices to begin with.

Under our side of the house, we are going to have a legitimate reason to criticize the government because you at the end of the day do not complicit in choosing the government to begin with. But going to the second thing right. The most important question, how it fits the Indonesian liberals interest to begin with? We say that the Indonesian liberals interest is they want a more liberation of Indonesia right. On how that currently Indonesia is very conservative to begin with to the extent of harming the liberal value like the interfaith marriage such for example that the leader that supposed to be coming from Muslim such for example or other liberals issue that is unable to be solved that is becoming the interest of liberal interest to begin with.

In the past, the reason why the Indonesia liberal forcing people to vote is exactly because they want some political leader that they see want to vote them going to champion this agenda to begin with right. But we don't think so right. Because the characterization of politicians are they easily betrays to begin with. Taking example how Jokowi such for example playing under the narrative of Indonesia Bersatu that is strengthening on saying that we are going to also champion more diverse people that is not only Muslim and Pribumi. At the end of the day, it betrays this community to begin with right on how such for example in the past, in the upcoming election, at the end of the day, Jokowi also only want to be in power given the fact therefore Jokowi choose is Makruf Amin such for 
example that is going to attract more Muslim voters, so sure that political candidate is not a favorable people for us to rely on our agenda to begin with. Why? Because what politician care is only the power and how they can sit in the parliament to begin with and hold the power. They are the characterization of people that really want to trade ideology to begin with. What is the difference under our side of the house, right? We say under our side of the house. Even, when the number of abstention increase, we say that this is going to create a necessity for political candidate such for example to show and also to analyze what actually wrong to begin with. At the end of the day, our voice going to be matter because the increasing number of abstention is also harming the political leader because that is going to decrease their legitimacy to begin with. Therefore, it is going to create an urgency for this politician to at the end of the day also cater the need of people and having discourse and also listening to them to begin with right.

But on the last thing right. On the idea of lesser evil that is going to be played by opposition to begin with. We don't think that lesser evil is a favorable principle to begin with because the idea of lesser evil is only applies when you are sure both figure is more evil than another. The problem with politics is we can never assure who is more evil to begin with right. Because in terms of campaign such for example, the political candidate can always playing the rhetoric and also popularizing the image to begin with. They are able even such for example brave to capitalize the issue, the rumor, of the family issues such for example in the time of campaign to begin with that makes you at the end of the day do not have an exact parameter of what evil is to begin with right. We say in the time when we are not sure to begin with which one is evil, it is more favorable for us to not choosing at all so we are not going to complicit and contributed to the downfall of this nation to begin with. We are very proud to open the case of the opening government.

\section{Deputy Prime Minister}

My mama said, if you see a toxic friend, it is better for you to cut off the friendship instead of you are creating a friendship to begin with, because that is exactly what this motion is. Ladies and gentleman, the whole argument of VM is contingent upon it is better for us to choose the lesser evil to begin with. If you're going to say that lesser evil is much worse, we are going to take this debate. First of all, the reason why you cannot differentiate whether that people is true lesser people or not because they're showing the lesser evil behavior during the campaign. That is exactly we are going to say to begin with. That is exactly being a strategy in politic. They're going to see toward people that they are lesser evil than their opponent. That is why people are going to consider that they are better. That people are going to choose them. That is exactly what happens in the United States of America. Trump's showing that they are lesser evil than Hilary Clinton. They offer opening immigrants toward our people, that is why people are choosing the Trump over Hilary Clinton.

But let us see in the status quo,the lesser evil become the incumbent government. They're creating a policy that making up a children separation. They're creating a policy that immigrants, immigrations. They're creating the wall. They're creating an abusive to all the immigrants. That is exactly things that we are going to prevent. At least we cut off all the toxic from the lesser evil. We are not giving thoseseat, enough. It is enough. We oppose. That is why the reason why the lesser evil cannot be justified. The only thing that the opposition could defend this is say to us why lesser evil could not making any policy that is moreevil when they have power. Because exactly when they have power, they can abuse 
to all the things that going to be happen because the power's in their own side. Even if they're going to say because that people are going to maintain their own image, the fact that they're having a lot of political, people are going to choose them and majority agrees with them. It is going even more worse. It is better for us to prevent it. Second rebuttal, things that we're going to say to you that basically the government side of the house, the opposition side of the house said to us that it is better for us to prevent the moreevil itself. We don't think this is going to prevent the moreevil itself because that is not going to make the general election being better. We bring you the fact in Tibos in the Sulawesi itself. It is better for us to not choosing at all because that is exactly the idea of people to begin with because that is exactly a concept of a people to begin with.

Why that is ok? In a worst scenario, we didn't get any politician and candidate. Why that is ok? Because at the end, we 're going to open the discourse that also relies toward the government. There is something wrong with this candidate. There is something wrong with this policy that we need to fix. At least, there is a discourse and at least there is something called as a review by that politician about the demand of the society that are going to be acknowledged even more because societies are choosing for not choosing instead of choosing why giving their voices toward certain candidates.

Lastly, the VM questions us who are the representation as a liberal itself. We think exactly as a liberal, we uphold the concept of appreciation the people choices to begin with. That is the idea of liberal. Liberal right now, it is not going to oppress everyone to forcing them to choose to begin with because that is the concept of everyone, because that is the concept of the liberal itself. But last, talking about the impact of the liberal, this at least better for us to choosing the lesser evil. That is the Jokowi and anything. Let us assume. Liberal right now needs to just gaining all the supporter from the society as much as possible to run their own policy. The reasons why Jokowi right now are engaging toward PPP and the other religious party are more difficult for them to create a policy that is more liberal. Because the reasons why Jokowi choose that Makruf Amin is because of a pragmatic reason to attract attentions of all the Islamic society. It is very difficult for them to create a liberal policy to begin with. Comparatively toward Prabowo, Prabowo is having the human right issue in the previous which is going to backstab all the liberal, all the liberal characterizations upon the society. They're going to make the society being difficult to which are going to be chosen by the liberal to begin with. We think that backlash the idea of a, the idea of liberal concept at all. But before that, let us closing. We think that is exactly the issue, because at least liberal, we're not going to choose the Prabowo or Jokowi because that is going to show the narrative of the liberal. That is going to appreciate that way. Coming toward the argument, why that is better for democratic itself? Me and Fatima believe that even if you're not choosing, there is also a decision. There is also a part of the democratic system. You're not going to choose because you're lazy and staying in the bed, but because you have a better consideration to not throwing all your voices to certain people. Fatimah also come out with the reasons if you're choosing people because of randomly and that people get the power, this is more even worse because that the idea of democracy. Everyone gets a same voice and also one voting is for another. You're going to throw it and making the power toward that people.

But, let us assume. What is the positive impact about this government? We think

if you're going to promote abstention toward the people right now, you're going to see and also able to track down the democractic system and also situation in the current situation. Why? Here is the thing. The idea of the general election is not only the idea of 
gaining or not only the idea of democratic party. It is not only the idea of the general election or the idea of gaining the president or vice president, but somehow it is being a tool for you to see and also to see the pattern of democracy inside of the country. The moment you're going to see that people are abstain, you're going to see to understand about the behavior of the people inside of that area. You're going to understand about the demand of the angry people toward the politic itself. Because that idea of the politic itself is you're going to understand that the people are hating the previous people that having the background of the human right violation. The rest of the society right now are hating to see the more conservative people to begin with. That is the idea of the democracy and also the benefit of the abstention itself.

Comparatively, if you're not abstain, you're randomly choosing someone. You're going to think that conservative is acceptable. That is why there is no review changes. There is no discourse changes to begin with. That is the pattern that is really difficult to track down. The track down is only able when there is someone who are saying that disagreement. That is why you're going to understand to begin with and society are going to see there is no problem at all in that way. We think lastly why that is better in the government side? We think the reasons why we're promoting abstention itself because we're going to have a behavior of certain people inside of the democratic itself. We're going to understand about what's the pattern of the democracy inside of the democratic country. They should come up toward this debate and saying that this abstention is going to give you a very worst, a very harmful toward this thing. Because even we take their worst scenario that even if we don't get any at all, any politician at all and even if we need to do the re-general election, at least we understand about what is the demand of a people. At least it is better for the general election.

Second thing, they need to defend how to gain more voices to the liberal society. Because in the status quo, the liberal people are being trusted. Society trust because they are acknowledged as a smart people. The moment we are going to oppress them,

there is narrative of the minor of society saying the liberal people. The oppression people are going to be justified because they are forcing you to choose. Even if they come toward the liberal idea, we do not think it could go that way. Because in old party in the current situation are standing in a less evil and lesser evil cannot be detected and you need to cut the toxic. As people speaking on behalf of a team who always sit at the back seat of every single national debating competition, we proudly propose.

\section{Leader of the Opposition}

Opening opposition stance is as follows. In the current political climate with Jokowi and Makruf Amin versus Prabowo and Sandiaga and other cases of lesser evil versus greater evil, what we must do as a liberal movement is to continue our campaign against abstention. You must vote because your vote matter to prevent the rise of a greater evil that will end up creating even greater harm. We think lesser evil is the best choice, we don't want another Trump. All right, two thing rebuttals.

Firstly, on the idea that abstention is a choice. Yes, we agree it is a choice, but choice is never an absolute ladies and gentleman. Why? We would argue that choice can always be limited when it comes to harms ladies and gentleman and this is a principle that even Indonesian liberals agree with. We agree with having an age limit for voting for example and they show how choice is not an absolutewhen it comes at the risk of harm. But secondly, note that unlike what they say we would say that criticism towards the liberal politician 
still can happen even under our side, even though you still vote for the lesser evil. Why? Because even then you still can speak up within that you still can speak in social media you still can say things towards your legislative and the liberal side of the lesser evil coalition will listen to you. Why? Because they understand that you are a significant part of their base and furthermore, they would like to get elected again in the future because most of the time they are a career politician ladies and gentleman. What does it mean? It means that should Indonesian liberal at one point be that irrespective of that. They will change anyway but unfortunately that is not the case today so that is why they make compromises and that is why we should also make compromises. For the rebuttals integrated, two things ladies and gentleman.

Number one, why lesser evil is the principle that you must take and number two the policy that will be implemented by the lesser evil and how it will advance our movement in the future. Let us begin with the principle and why lesser evil is the principle that you must take. What is the stance of Indonesian liberal? The stance is they would like to have moreright ladies and gentleman. Equal rights fighting for minority and those wives. Now why is that, that within achieving this right we must be pragmatic. Number one, let us make a comparative of harm, right. We think that the harm will be much greater should you choose of the greater evil. No, in the case of lesser evil, even though it is not perfect we still think that the liberal side of the camp can reign in this so-called evil within the lesser evil coalition. We think that people like Jokowi can reign the likes of Makruf Amin. Why? For example, in that case, vice president power in Indonesia is relatively small. Their role is those of an advisor and their duties at somewhat ceremonial. Furthermore, Jokowi is younger and healthier than Makruf Amin. Replacement is particular unlikely. What is the comparative that they will be risking.

The comparative is that voting on nothing means that you are going to give that food to a greater evil that can rise up. This is the case of Prabowo Sandiaga Uno which is much more dangerous. Why? Because there's a clearer bad track record, note that Sandiaga uno is one of the perpetrator of 212 that at the end of the day attack Ahok. Note that Prabowo militarism in 1998, kidnapping is ordered by him and the only reason why he missed acquittal is simply because of political power. Wise harm-prevention, the most importantly and a principle you must take. Because the question is on who are you representing as the liberal movement ladies and gentleman. You are representing the people who are the most vulnerable. You are representing minority that is going to be discriminated. You are representing on the rights that have been taken all the time and the moment you just do not vote you have to split the food of your camp that we solve without a potential win for the greater evil.

It means that your people will suffer even further and then you're suffering so much. We think that the best we can do is prevent greater suffering for these people. Why is sustain even more important? Because the comparative is as follows. Note that in the event that the greater evil rises to power, your future fight will be harder as well. Why? Because once they rise to power, they can do the things like changing the constitution, policy, and raging the parliament ladies and gentleman, making it harder for you to even fight in the future. What it means that they will not only lose today, but we will lose in the future ladies and gentleman. But secondly, we would argue that this is consistent ladies and gentleman. Why? Because liberals have been making compromises in Indonesia all the time anyway, ladies and gentleman. For example, the liberal party PSI is very Ahok supporter, but at the end of the day, they choose to support Makruf Amin anyway. Ahok expressed interest in the 
campaign for Jokowi and furthermore, we have been making compromises anyway. Jokowi makes compromises when he runs with Jusuf Kalla such as by not prosecuting the 1998 . So even in term of principles, we have been consistent, because that is what we have done all the time to reach this level ladies and gentleman.

But second argument, on the policy that will be implemented and how it will benefit our movement. Yes, before that. Yes, he is pandering to a lot of people. That is exactly the point, he cannot rely on the liberal vote solely in order to get Islamist vote that is particularly powerful. That is the reason why Ahok's foolish ladies and gentleman and that is why lesser evil is important, right. Ok, let us talk about policy, ok. We think that at the end of the day the question that we must ask is that how to make our movement stronger. Let us begin at how much power that our movement have right now. We think that power that we have is limited. It is concentrated only in the likes of young people and urban Java area for example. So, let us talk about our movement, how this candidate, the lesser evil policy will eventually strengthen our movement further.

Firstly, let us talk about our base camp, the likes of Java urban area where our movement is significantly stronger. How to make it even stronger ladies and gentleman? We need the people to associate our movement with a positive message and a positive branding and we think that this requires our lesser evil candidate to be elected first so that the people that exist in the grey area that are unsure about what to think about our movement will eventually associate us with a greater power, right. Why? Because the lesser evil candidate of the liberals are often times much more development and economic centric compared to the greater evil that are much more military and also morality centric. This is the case with Jokowi for example with this infrastructure programming in his campaign versus NKRI Bersyariah which is a key part of his campaign or in the government election, this is the case with Ridwan Kamil Economic Policy versus Hidayat Syahruin Conservative Strengthening in west Java. Now why is this good when we choose the more economic and development centric candidate of the lesser evil? Because it will lead to future positive reinforcement that is because this area of Java is much more concern to economic and they're less puritan, so we strengthen our base at that point.

But secondly on the non-Java area, in area in which we are less powerful. We think

that despite this area is having a bigger cultural affiliation, at the end of the day, this is as to why there are cases because they lack of other narrative. We think that opening an economic development means that they will be a new narrative coming towards them. What is that? Number one, through our infrastructure, when we build communication tower, when we build internet, there is a counter view point that can finally penetrate this area ladies and gentleman. But secondly, not only we're bringing this narrative to the table, we think that economy on its own is a good narrative. Why? Because in this area, inequality is a very big issue and we think that helping and solving it at the end of the day will be an impact and a benefit that is directly seen by this people. What does it mean? It means that they will see that this liberalism brings benefit and it brings a direct benefit compared to the lesser evil of militarism. Other than that, we'll get a better association that will continue to the future, that is how we sustain our movement. We proudly oppose.

\section{Deputy Leader of the Opposition}

Before I move on to my contentions and close the case of opening opposition,let me first contextualize and clarify to you what does lesser evil actually means. We think under opening opposition, lesser evil does not mean that there is a different type of harm,but it is 
only the degree of harm that is different ladies and gentleman. Let us contextualize how does Indonesian politics works. Indonesian politics is not like United States politics that has a clear distinction about for example are your policy socialist or your policy capitalist. If you ask politician from Partai Kebangkitan Bangsa and Partai Persatuan Pembangunan for example about what is their economic policy that is different, they will not have any answer at all ladies and gentleman.

Moreover, we also argue that Indonesian politics is also not about how much of a role of Islam play in public life. Because Prabowo and Sandy are supported by GNPF Ulama and 212 movement and Jokowi at the same time has Makruf Amin that is supported by MUI. What I am trying to say here is that this is a very important framework since this proves that Indonesian politic is inherently about pragmatism and given that context, Indonesian liberal as the movement should be pragmatic as well. What we are going to prove to you under opening opposition as the marginal benefit that support our pragmatism is significantly beneficial to our liberal movement at the end of the day. That is explicit stance and exclusive contributions coming from the opening opposition. Before I move on, I am going to close the case of opening opposition by talking about two things. One, how is lesser evil different from the greater evil and secondly, what strategy liberal movement in Indonesia is pursuing right now and why embracing lesser evil is the only way to go. First of all, let us talk about how is lesser evil different than the greater evil. Because opening government essentially claim that can be morebad that the greater evil. No.

Number one, note that lesser evil candidate has more counterbalance ladies and gentleman. Note that this is impossible for us to assume that Jokowi will want Indonesia to go to Islamist state as much as Prabowo is simply because the constituents that support Jokowi is even more liberal in the first place. For example, they have Partai Solidaritas Indonesia. They have National Democrat that backed by Surya Paloh that is famous for being a secular person which has pragmatic interest to ensure that this does not happen. On the comparative, Prabowo has less counterbalance which means that the degree of harm will not be acquitted at the end of the day. And second and the most important, note that each different political candidate wants to be different from each other. Because that is the only way in which they can maintain their consistency and to gain votes at the end of the day. If Jokowi gets even more greater evil that means that he is conceding to Prabowo stance and that will definitely be perceived by the voter as betrayal to the voters to begin with ladies and gentleman.

That is why we argue that Jokowi does not have any incentives to do this at all. With this clarification, let us move to the second and the most important clash of this debate about what strategy of liberal movement in Indonesia is pursuing right now. Note that this debate, the most important contention must only come from the one that considers the context of what strategy of liberal movement in Indonesia is pursuing right now and why does marginal benefit further the movement even further. To this, I am going to talk about two layers.

Number one. What we are doing right now is that we are protecting minorities and secondly what we are doing right now is that we are making compromises for the sake of getting even more support. First of all. Let us talk about protecting minorities. In the status quo right now, many liberal movements implement concrete project. However, it is done in a cover manner. For example, in the status quo right now in many rural areas in Indonesia, many some branches of Islamist Indonesian give away condom for free in order to prevent sexually transmitted disease in certain area. Of course, this movement is done in secrecy 
because it is going to be controversial if it is going to the public in the first place ladies and gentleman.

The problem that might obstruct all this campaign that we are doing right now is the platform that we can use will be taken down ladies and gentleman. What they may be talking about? We are talking the high likelihood of FPI to do progressive centers for example which are the center of the project that we are doing right now. But what I am trying to say here is that marginal benefit is significant in order for us to sustain this movement in the first place ladies and gentleman. Because it will be published, it will create controversy and that we will have the high likelihood to make the entire public explicitly goes against us. This comes in various forms, in terms of boycott, in terms of sexual exclusion, even in the worst case in the form of institutional take down of our movement at the end of the day.

We think that marginal benefit protects minorities significantly and that is the benefit that the closing government and opening government cannot possibly neglect to this debate. That is the first thing. And second and the most important, what we are doing right now is that we are making compromises ladies and gentleman. This clash, this layer will discuss how do we get even more support as the liberal movement. Given my opening, I have already established that Indonesian politic is not about ideology. It never is. But it is about pragmatism. This kind of narrative is something that is already recognized by the majority of Indonesian people. Given this, I am going to talk about two kinds of actors. Number one, I am going to talk about the kinds of people living in the grey area. Secondly, I am going to talk about the actual liberal themselves. First of all, let us talk about the kind of people living in the grey area. This is the reason as to why VM's context becomes very important because the majority of Indonesian people do not care much about ideology. But what they need are things like protection and economic empowerment. Those are completely pragmatic reasons ladies and gentleman. We must be able to convince them that we are also pragmatic as well. We will also champion the pro step by step empowerment to the extent that you are able to achieve your ideal goal at the end of the day.

Because note that it is impossible for us to make Indonesia is completely liberal country for the next five to ten years. It takes of an extremely long time which unfortunately might not happen in our lifetime ladies and gentleman. It is something that must be supported here and we think under their side these people will not have any incentives to support us ladies and gentleman. That is the first people.

And the second people I am going to talk about are the actual liberal. Who are we talking about? We are talking about organizations like Arus Pelangi for example that currently tries to lobby the DPR for the government to not discriminating like homosexuality and so on and so far. Note that this organizations does not support any political candidate at all. What this movement needs are only pure platform to advance their idea and these ideas are independent of any political party ladies and gentleman. All of these things will feel betrayed. In the intentions in which we explicitly stated to them that we must not provide them any platform by not supporting the lesser evil candidate, at the end of the day we think that this will lead to a significant harm because at the end of the day the liberal movement will be fractured because under one side we have liberal movement that does not support the lesser evil but on the other hand, we have a branch of liberal movement that tries to implement as much as many concrete projects as possible but it only needs platform for you to do so. 
We think that coherence of identity and coherence of platform and coherence of project that we do is something that is more important. What is the conclusion of this debate? Note that Indonesian politic is inherently pragmatic and they must show that why does not embracing lesser evil will further enhance this pragmatism. We close the case of opening opposition.

\section{LIST OF ABBREVIATION}

WUDC (World University Debating Championship)

NUDC (National University Debating Championship)

PM (Prime Minister)

DPM (Deputy Prime Minister)

DLO (Deputy Leader of the Opposition)

LO (Leader of the Opposition)

LD (Lexical Density)

GI (Grammatical Intricacy)

OG (Opening Government)

CG (Closing Government)

OO (Opening Opposition)

$\mathrm{CO} \quad$ (Closing Opposition) 